\title{
Survey of general practitioners' attitudes to AIDS in the North West Thames and East Anglian regions
}

\author{
ROSEMARY BOYTON, GRAHAM SCAMBLER
}

\begin{abstract}
As the numbers of people suffering from human immunodeficiency virus infection and the acquired immune deficiency syndrome (AIDS) increase, so will the contribution to care required from general practice. A postal questionnaire survey was therefore carried out among general practitioners in the North West Thames and East Anglian regions to determine their attitudes to AIDS and the issues it raises for them. One hundred and thirty seven questionnaires were returned (response rate $\mathbf{5 7 \%}$ ) and four factors underlying the doctors' attitudes identified; these concerned disease control, general practitioner care, patient support, and perception of seriousness. There were wide divergencies of attitude among the general practitioners, younger doctors being more in line with specialist thinking on AIDS than older colleagues, and evidence of important gaps between policies advocated by AIDS specialists and bodies of opinion in general practice.
\end{abstract}

Attitudes to AIDS in general practice may partly be a function of personal experience; further study is required.

\section{Introduction}

The acquired immune deficiency syndrome (AIDS) continues to be a focus of considerable medical and social interest and concern. As the incidence of the disease increases, so too will the number of patients presenting to general practitioners and the potential for these doctors to engage in continuing care. It is therefore important that we should know something of the attitudes of general practitioners to AIDS and patients with the disease. Surprisingly little pertinent research has been published and the only study that we know of which directly addresses these issues is too restricted to contribute more than marginally to our understanding of how general practitioners are thinking and why. ${ }^{1}$ The following study is a provisional attempt to fill this important gap in research.

\section{Methods \\ Reports from the Communicable Disease Surveillance Centre show that nearly a third of all positive antibody reports in England, Wales, and Northern Ireland and nearly half of reported cases of AIDS in Britain between 1 December 1984 and 31 December 1986 came from the North West Thames region. Over the same period East Anglia accounted for less than $3 \%$ of all positive antibody reports and less than $1 \%$ of all reported cases of AIDS. ${ }^{2}$ As we thought that differential exposure to human immunodeficiency virus (HIV) infection may have an important bearing on general practitioners' attitudes, samples were drawn from within the North West Thames and East Anglian regions (that is, including all general practitioners on the family practitioner committee lists operating in and around the Camden area and Cambridge respectively).}

Royal Free Hospital School of Medicine, London NW3 2PF ROSEMARY BOYTON, BSC, clinical student

Academic Department of Psychiatry, University College and Middlesex School of Medicine, Wolfson Building, London W1N 8AA GRAHAM SCAMBLER, BSC, PHD, senior lecturer in sociology

Correspondence to: Dr Scambler.
Postal questionnaires were designed to cover the backgrounds of the general practitioners, characteristics of their practices, and 40 attitude statements with fixed choice response categories according to the Lickert format (strongly agree, agree, uncertain, disagree, strongly disagree). The attitude statements mostly concerned the perceived seriousness of AIDS, general practitioners' role in care, screening, and modes of control. A total of 240 questionnaires with a covering letter were sent out in February 1987157 to general practitioners working in the North West Thames region and 83 to general practitioners in East Anglia; 137 were completed and returned, 81 from North West Thames and 56 from East Anglia. A further 16 were returned too late for inclusion in the analysis. Thus $57 \%$ of the questionnaires distributed were analysed, an acceptable return for a study relying on postal questionnaires.

\section{Results}

\section{PERSONAL EXPERIENCE}

Forty eight (35\%) of the 137 respondents had seen one or more patients with HIV infection. More of those practising in the North West Thames region $(34 ; 42 \%)$ had done so than of those in East Anglia (14;25\%).

\section{ATTITUDES AND OPINIONS}

In this study "strongly agree" and "agree" have been interpreted as assent to attitude statements and "strongly disagree" and "disagree" as dissent.

Perceived seriousness of AIDS-Ninety six doctors (70\%) regarded AIDS as a serious problem, though $26(19 \%)$ thought it less serious than "some would have us believe." A total of 111 of 136 doctors (82\%) supported the notion of an integrated research programme into AIDS funded by government. As far as health education was concerned an appreciable minority of doctors $(37 ; 27 \%$ ) thought that funding could more usefully be targeted in areas other than AIDS. Ninety six (71\%) of 135 doctors were pessimistic about the hope of a cure or vaccine in the near future.

Prevention-The vast majority of respondents $(127 / 135 ; 94 \%)$ agreed that greater public understanding was "the most effective single weapon we have in the fight against AIDS." A total of $106(77 \%)$ of all 137 doctors surveyed were in favour of free needles being made available to drug abusers and 94 of $136(69 \%)$ of condoms being freely available in chemists as well as sexually transmitted diseases clinics.

Caring in general practice-Most respondents (93/136; 68\%) thought that general practitioners should be engaged in the ongoing treatment of patients with AIDS and only 20 of $136(15 \%)$ expressed clear dissent. Sixty nine of 134 doctors $(51 \%)$ were in favour of additional resources being made available to facilitate this work. Four fifths of the sample $(111 / 137 ; 81 \%)$ thought that general practitioners should receive special training in the care and management of patients with AIDS but only $85(77 \%)$ of these doctors ( $62 \%$ of the total sample) wanted such training themselves. Only 20 of 126 doctors (16\%) rated general practitioners' knowledge of AIDS as "good" or "very good," yet just over one third of all respondents $(48 ; 35 \%)$ considered that their own knowledge came into these categories.

Screening-General practitioners' attitudes towards screening were particularly interesting, given the recent statements from the BMA and other bodies. Exactly half thought that HIV antibody screening should be routinely available in general practice. One hundred and sixteen of 136 respondents $(85 \%)$ thought "adequate counselling" to be necessary before testing, but only 56 of all $137(41 \%)$ believed that general practitioners were qualified to provide such a counselling service. Ninety of 136 doctors $(66 \%)$ thought that patients should not be tested without their knowledge and permission. Nevertheless, $79(58 \%)$ of the 136 doctors (including $23(26 \%)$ of the 90 who stated that they were opposed to testing without consent) judged there to be "certain circumstances" when testing without consent was acceptable; examples cited were child patients, pregnant women, preoperative patients, blood donors, psychopathic patients, patients detained under the Mental Health Act, and cases in which the "patient's 
identity is unknown and the result used for prevalence research." Of 128 respondents, $109(85 \%)$ were against the compulsory screening of the whole population, with only $10(8 \%)$ approving. Participants were also asked to respond to statements advocating compulsory screening for six specific population subgroups (table I). For four of these (people entering the country, especially from Africa; intravenous drug abusers; patients with haemophilia; infants born to infected mothers) more respondents favoured than opposed compulsory screening. Only for the last category (infants born to infected mothers), however, was the majority a clear one, two thirds of the sample recommending compulsory screening (table I).

Notification of people with HIV infection-Most respondents (125/136; $92 \%$ ) thought that they should be notified if any of their patients were found to be HIV antibody positive. A much smaller proportion $(47 / 130 ; 36 \%)$ thought that patients with HIV infection should be notified to a government body. represents the view that the control of AIDS is paramount and should override individual civil liberties. The factor had positive loadings on the compulsory screening of all the risk groups (ranging from 0.919 to 0.731 ) and the population as a whole $(0.403)$; compulsory identity cards for HIV antibody positive patients $(0.490)$; an AIDS free certificate being required before granting entry visas to Britain (0.629); sexual relations between male homosexuals being made illegal again $(0.342)$; and HIV antibody positive patients being treated according to society's rather than their own individual interests $(0.535)$. There was a negative loading on the view that a national screening programme would isolate victims and prove both medically useless and harmful to society $(-0 \cdot 310)$.

Factor 2 (general practitioner care) accounted for $12 \%$ of total variance. This factor reflects the view that general practitioners should be concerned in the continuous care of patients with AIDS. It had positive loadings on general practitioners receiving training-generally $(0 \cdot 807)$ and personally $(0 \cdot 811)$ -

TABLE I-Attitudes to compulsory screening for population subgroups

\begin{tabular}{|c|c|c|c|c|c|c|}
\hline Attitude statement & $\begin{array}{l}\text { No of } \\
\text { respondents }\end{array}$ & $\begin{array}{c}\text { No (\%) } \\
\text { strongly agree }\end{array}$ & $\begin{array}{c}\text { No (\%) } \\
\text { agree }\end{array}$ & $\begin{array}{c}\text { No }(\%) \\
\text { uncertain }\end{array}$ & $\begin{array}{c}\text { No (\%) } \\
\text { disagree }\end{array}$ & $\begin{array}{c}\text { No (\%) } \\
\text { strongly disagree }\end{array}$ \\
\hline \multicolumn{7}{|l|}{ There should be compulsory screening of: } \\
\hline People entering Britain, especially from Africa & 135 & $25(19)$ & $36(27)$ & $26(19)$ & $28(21)$ & $20(15)$ \\
\hline Homosexual and bisexual men & 135 & $23(17)$ & $24(18)$ & $20(15)$ & $48(36)$ & $20(15)$ \\
\hline Intravenous drug abusers & 136 & $28(21)$ & $36(26)$ & $24(18)$ & $30(22)$ & $18(13)$ \\
\hline Patients with haemophilia & 136 & $31(23)$ & $40(29)$ & $22(16)$ & $26(19)$ & $17(13)$ \\
\hline Sexual partners of all the above groups & 135 & $23(17)$ & $24(18)$ & $17(13)$ & $48(36)$ & $23(17)$ \\
\hline Infants born to infected mothers & 136 & $41(30)$ & $51(38)$ & $14(10)$ & $18(13)$ & $12(9)$ \\
\hline
\end{tabular}

TABLE II-Attitudes to modes of control

\begin{tabular}{|c|c|c|c|c|c|c|}
\hline Attitude statement & $\begin{array}{c}\text { No of } \\
\text { respondents }\end{array}$ & $\begin{array}{c}\text { No }(\%) \\
\text { strongly agree }\end{array}$ & $\begin{array}{c}\text { No (\%) } \\
\text { agree }\end{array}$ & $\begin{array}{c}\text { No }(\%) \\
\text { uncertain }\end{array}$ & $\begin{array}{c}\text { No (\%) } \\
\text { disagree }\end{array}$ & $\begin{array}{c}\text { No (\%) } \\
\text { strongly disagree }\end{array}$ \\
\hline $\begin{array}{l}\text { An AIDS free certificate should be required before granting entry visas to Britain } \\
\text { Patients found to be HIV antibody positive should carry an identity card } \\
\text { Sexual relations between male homosexuals should return to being illegal }\end{array}$ & $\begin{array}{l}136 \\
136 \\
135\end{array}$ & $\begin{array}{r}12(9) \\
7(5) \\
11(8)\end{array}$ & $\begin{array}{r}25(18) \\
21(15) \\
3(2)\end{array}$ & $\begin{array}{r}21(15) \\
19(14) \\
9(7)\end{array}$ & $\begin{array}{l}62(46) \\
69(51) \\
63(47)\end{array}$ & $\begin{array}{l}16(12) \\
20(15) \\
49(36)\end{array}$ \\
\hline
\end{tabular}

Modes of control-Table II summarises responses to three statements relating to control, concerning entry visas to Britain, carrying identity cards, and return to legislation against male homosexuals. In each case most general practitioners were opposed. Interestingly, however, as many as one in four favoured AIDS free certificates before the granting of entry visas, one in five a system of identity cards for people with HIV infection, and one in 10 the reintroduction of legal penalties for sexual relations between male homosexuals.

Employment-Finally, there were three attitude statements on employment. Eighty two $(60 \%)$ of 136 respondents thought that there should be no obligation on employees to disclose their infection or submit to medical tests at their places of work; only 26 doctors $(19 \%)$ dissented. One hundred and twenty four $(91 \%)$ of the 136 doctors believed that carriage of AIDS was not "an acceptable basis for dismissal from employment." Indeed, 100 doctors (74\%) considered that employers who dismiss AIDS carriers or discriminate against those whom they think may be at risk should face legal action.

\section{FACTORS DESCRIBING ATTITUDES}

The distribution of attitudes presented above is of interest in its own right, largely because it stands to inform current debates about AIDS and appropriate reactions to it. But it tells us nothing of the factors underlying the sometimes pronounced attitudinal divisions within general practice. To contribute to this further task a factor analysis was undertaken. This method identifies underlying, not directly observable constructs based on a set of observable attitudinal variables. Factors were extracted by means of principle components analysis and a varimax rotation performed. Four factors were incorporated in the model, accounting between them for $44 \%$ of the total variance. These were conceptualised as disease control, general practitioner care, patient support, and perception of seriousness. The figures in parentheses below represent the significant loadings in the factor matrix after the varimax rotation. A significant loading was defined in terms of the Burt and Banks formula.

Factor 1 (disease control) accounted for $21 \%$ of total variance. Factor 1 in the management and care of patients with AIDS; screening for AIDS being offered routinely by general practitioners $(0 \cdot 319)$; and extra resources being made available to facilitate participation by general practitioners $(0.557)$. There were negative loadings on the views that it is currently not practicable for general practitioners to engage in care $(-0.561)$ and that the provision of continuous care is not part of the general practitioner's role $(-0.659)$.

Factor 3 (patient support) accounted for $6 \%$ of total variance. This factor represents the view that patients require support and that the control of AIDS should be pursued without resorting to statutory or other discriminating measures against sufferers. This factor had positive loadings on counselling being necessary before testing for AIDS (0.648); drug abusers being given free needles $(0.713)$; and employers who dismiss or otherwise discriminate against those infected or at risk of infection facing legal action $(0 \cdot 316)$. There were negative loadings on the views that it is not the general practitioner's task to provide continuous care $(-0.413)$ and that sexual relations between male homosexuals should be made illegal $(-0 \cdot 729)$.

Factor 4 (perception of seriousness) accounted for $5 \%$ of total variance. This fourth factor represents the conviction that AIDS is currently a severe problem. It had positive loadings on the need for a massive integrated research programme of research on AIDS (0.596) and negative loadings on the views that AIDS is not as serious as some have suggested $(-0.804)$ and that funding on health education could more usefully be deployed in areas other than AIDS (-0.758).

The relations between various characteristics of general practitioners and their practices and these four factors were examined. Factor scores for each of the four factors were computed for each general practitioner. These were coded as high, intermediate, or low (that is, a high score indicating agreement with a factor and a low score disagreement). Table III shows the nature and strength of the relations between five variables (sex, age, area of practice, single or group practice, personal experience of HIV infection) and each of the four factors in terms of the ratios of high to low scores (that is, + signifies a tendency to agree with a factor and - a tendency to disagree with a factor). The possible effect on attitudes of personal experience of patients with HIV infection was particularly interesting. Experience seemed to have no effect on the perception of the seriousness of AIDS but was related 
TABLE III-Relations between selected demographic variables and four factors describing attitudes

\begin{tabular}{|c|c|c|c|c|}
\hline \multirow[b]{2}{*}{ Demographic variables } & \multicolumn{4}{|c|}{ Factors } \\
\hline & $\begin{array}{l}\text { Disease } \\
\text { control }\end{array}$ & $\begin{array}{l}\text { General practitioner } \\
\text { care }\end{array}$ & $\begin{array}{l}\text { Patient } \\
\text { support }\end{array}$ & $\begin{array}{l}\text { Perception of } \\
\text { seriousness }\end{array}$ \\
\hline \multicolumn{5}{|l|}{ Sex: } \\
\hline Male & $1 \cdot 4+$ & $1 \cdot 0$ & $2 \cdot 0-$ & $1 \cdot 1+$ \\
\hline Female & $2 \cdot 0-$ & $1 \cdot 1-$ & $1.5+$ & $1 \cdot 3-$ \\
\hline \multicolumn{5}{|l|}{ Age (years): } \\
\hline$<40$ & $2 \cdot 5-$ & $5 \cdot 5+$ & $2 \cdot 0+$ & $3 \cdot 2+$ \\
\hline $40-54$ & $2 \cdot 9+$ & $1 \cdot 3-$ & $1 \cdot 4-$ & $1 \cdot 7-$ \\
\hline$\geqslant 55$ & $1 \cdot 9+$ & $2 \cdot 5-$ & $3 \cdot 3-$ & $1 \cdot 7-$ \\
\hline \multicolumn{5}{|l|}{ Area of practice: } \\
\hline East Anglia & $1 \cdot 2+$ & $1 \cdot 1-$ & $1 \cdot 4-$ & $1 \cdot 0$ \\
\hline North West Thames & $1 \cdot 1-$ & $1 \cdot 1+$ & $1 \cdot 7-$ & $1 \cdot 0$ \\
\hline \multicolumn{5}{|l|}{ Single $\%$ group practice: } \\
\hline Single & $1.9+$ & $10 \cdot 0-$ & $33 \cdot 3-$ & $1 \cdot 1+$ \\
\hline Group & $1 \cdot 1-$ & $1 \cdot 4+$ & $1 \cdot 0$ & $1.7+$ \\
\hline \multicolumn{5}{|l|}{$\begin{array}{l}\text { Personal experience of } \\
\text { HIV infection: }\end{array}$} \\
\hline None & $1 \cdot 3+$ & $1 \cdot 1-$ & $2 \cdot 5-$ & $1 \cdot 1-$ \\
\hline One or more cases & $1 \cdot 3-$ & $1 \cdot 3+$ & $1.5+$ & $1 \cdot 1-$ \\
\hline
\end{tabular}

to disagreement with strong social and legal measures of disease control and agreement with both participation of the general practitioner in care and measures of patient support.

\section{Discussion}

Postal questionnaires relying predominantly on fixed choice response categories have limitations and it would be foolish to suggest that the complexity of AIDS related issues can fully or properly be represented and explored by such means. The objective of this study was to throw some much needed light on current thinking in general practice on matters of increasing and major concern. Adler has predicted that "as the number of cases increases it will be essential for the community services to be able and willing to cope." "' The results are of particular interest because they suggest wide divergencies of attitude among general practitioners. They testify also to the existence of important gaps between the policies advocated by AIDS specialists and bodies of opinion in general practice. For example, whereas specialists in both Britain ${ }^{4}$ and the United States ${ }^{5}$ have advised against a policy of compulsory screening except in extremely rare circumstances, this study indicates that between a third and a half of general practitioners may favour compulsory screening for each of the main groups at risk.

It is one thing to document attitudes and quite another to account for them. This study has contributed to the process by identifying four factors underlying general practitioners' attitudes and considering possible links between these factors and characteristics of the general practitioners and their practices. Some of these links were predictable. For example, younger doctors appear to be more in line with specialist thinking on AIDS than their older colleagues, with lower scores on disease control and higher scores on general practitioner care, patient support, and perception of seriousness. Other links may warrant further, more focused research. For example, general practitioners who have seen HIV antibody positive patients are apparently closer to specialist opinion than those who have not, regardless of age. It may be, therefore, that attitudes in general practice are partly a function of personal experience. There is a need for hypotheses like these to be examined. This need, however, can most usefully be met if such research is conducted in the context of a more broadly based concern with the interplay between the attitudes and values of doctors and those of lay people, and between the values that doctors choose to enact and those that they are constrained to enact by the society in which they practise.

We thank those general practitioners who took part in the study and also Drs James Thompson and Graham Hart for helpful advice.

\section{References}

1 Searle E. Knowledge, attitudes and behaviour of health professionals in relation to AIDS. Lance 1987; : $26-8$.

2 PHLS Communicable Disease Surveillance Centre. Communicable disease report 86/53. London: PHLS Communicable Disease Surveillance Centre, 1987.
P

3 Adler M. Care for patients with HIV infection and AIDS. Br Med f 1987;295:27-30.

4 Miller D, Jeffries D, Green J. Should testing ever be routine? Br Med J 1986;292:941-3.

5 Health and Policy Committee. Acquired immunodeficiency syndrome. Ann Intern Med 1986;104 $575-81$.

(Accepted 13 November 1987)
We have several times noticed the efforts that are being made to provide food for school children, and have pointed out that one of the greatest difficulties is the economic side of the question - to do the greatest amount of good with the least possible weakening of the sentiment of self-dependence in the parents. That a large number of school children are underfed or starving appears to be demonstrated; it has also been shown that the power of body and brain suffers therefrom. In too many cases starvation is chronic and incapable of permanent relief; in other neighbourhoods the relief may be required as an exceptional matter, during times of special depression in trade. We have ourselves seen a large Board School in the jewellers' quarter of Birmingham where most of the children appeared to be starving and exhausted in consequence; this was explained as owing to the local depression of trade. Here was a case where a temporary supply of cheap or even free food at the school might have been most useful in arresting the tendency to disease, and in aiding development. The Charity Organisation Society, in a valuable report recently issued on charity and food, points out many facts founded upon evidence which they have collected; reports have also appeared in Birmingham, Liverpool, and other large towns on the work done there. The starving children often appear to show more signs of daintiness than of hunger, which seems to indicate the dyspepsia of inanition. The apparatus used for cooking makes much difference in the economy of the meals, as well as in their success in point of tastiness. To leave the children attending school without dinner for three months is likely to result in a delay of growth and development of body and brain which would take a long time to overtake. Temporary relief in periods of distress, when the children continue their school work, seems very desirable-a true work of charity, and one not too costly, though requiring much personal labour on the part of managers and visitors. If relief is to be temporary, it cannot be selfsupporting; if dinners for school children are to become a permanent institution they ought not, we think, to be provided by charity or by the State, but by commercial resource. The numerous experiments made by charitable people have afforded much information upon which commercial enterprise may be founded; but it seems hardly likely that selfpaying dinners can be provided, unless accommodation is to be had at or near the schools rent free. If it be shown that there is a permanent demand for dinners at or near large schools at a commercial price, the necessity of the case might be met on the same basis as at some of our colleges; let rooms appropriately fitted be provided by the public, and let at low rentals to contractors. It ought also to be arranged that such rooms, being independent of the schools, should be open on Saturdays and during the holidays, if wanted.

(British Medical fournal 1888;i:146) 